\title{
Análisis sobre la reputación de marca, las emociones y la confianza como formadoras de la satisfacción del turista
}

Rafael Fabricio Matos

Cámara

Universidad Tecnológica de Cancún

rmatos@utcancun.edu.mx

\section{Sonia San Martín}

Gutiérrez

Universidad de Burgos sanmargu@ubu.edu.es

\section{Resumen}

Este trabajo propone un modelo causal de múltiples relaciones entre la reputación de marca de un destino turístico y los efectos de las emociones como estímulos de respuestas del turista durante su visita; asimismo, se desea saber cómo estas variables establecen su confianza para conseguir su satisfacción. El estudio se contrastó empíricamente para el caso del destino turístico ecoarqueológico mundo maya-México; por ello, se desarrolló un marco teórico multidisciplinar con aportaciones de la teoría de señales, la teoría de emociones en marketing y el marketing de relaciones; este modelo desarrollado y propuesto se centró en dos enfoques: el cognitivo-afectivo de la satisfacción y el de factores afectivos procedente de la psicología ambiental. Los resultados que se obtuvieron corroboran la mayoría de nuestras hipótesis y arrojan resultados importantes en el ámbito académico y profesional. Así, la reputación del destino, las emociones y la confianza del consumidor resultan determinantes sobre la satisfacción del turista durante su visita a un destino turístico.

Palabras clave: reputación, confianza, emociones, satisfacción, destino turístico. 


\title{
Analysis of brand reputation, emotions, and trust as stimuli for tourist satis- faction
}

\begin{abstract}
This paper proposes a causal model of multiple relationships between the brand reputation of a tourist destination and the effects of emotions as stimuli for tourist responses while visiting; it also aims at finding out how these variables provide trust to ensure their satisfaction. The study has been empirically compared for the case of an eco-archaeological tourism destination, Mayan World-Mexico. To this purpose, we develop a multidisciplinary framework with inputs from the signal theory, the theory of emotions in marketing and relationship marketing. Additionally, the developed and proposed model conceives two approaches: the satisfaction cognitive-affective approach and the affective factors approach from environmental psychology. The obtained results confirm most of our hypotheses and show interesting results in the academic and professional fields. Thus, the reputation of destination, consumer emotions and trust are critical for tourists' satisfaction during their visit to a tourist destination.
\end{abstract}

Keywords: reputation, trust, emotions, satisfaction, tourist destination.

\section{Introducción}

En el ámbito de los destinos turísticos se perciben cambios que han hecho al viajero más exigente, modificando sus valores y preferencias; esto por causa de la información y de su mayor experiencia de viaje, de la globalización de la oferta y de la exigencia de la demanda en el sector turístico. Autores como Ramírez (2006) apuntan que el problema del turismo se acentúa por la falta de conocimiento sobre la disciplina del marketing. El producto turístico, aun cuando sus características son muy diferentes a los productos industriales, no difiere en su tratamiento a las técnicas y aplicaciones del marketing como herramienta de estudio del mercado turístico. Sin embargo, observamos que por su naturaleza el producto turístico se caracteriza por ser consumido en el lugar de origen, lo que rompe con el esquema tradicional del marketing de dirigir el producto hacía el mercado. Por ello, "los destinos turísticos deben ofrecer una experiencia integral basada en la calidad y la diferenciación, aportando mayores niveles de utilidad y valor emocional a los cada vez más sofisticados y exigentes turistas" (San Martín, 2005, p. 4). Es por eso que el destino turístico no sólo se debe delimitar de forma geográfica, pues de igual forma supone un conjunto de atributos económicos y emocionales que se ofrecen al turista. 
En las líneas que siguen se analiza un modelo que muestra diferentes aportes. En primer lugar, la teoría de señales (aspectos económicos) observa que los consumidores recurren a estas señales para inferir las características de los productos debido a la existencia de información incompleta y asimétrica en los mercados (Selnes, 1998; Erdem, 1998; Kirmani y Rao, 2000; San Martín, 2003). En concreto, las señales pueden dar al turista información permitiéndole evaluar las distintas alternativas para poder tomar una decisión de compra satisfactoria. En consecuencia, el turista toma decisiones basadas en la información de la cual dispone y a partir de señales transmitidas por el vendedor (Kirmani y Rao, 2000); en nuestro caso, la señalización se da por una reputación de marca positiva del destino turístico.

En segundo lugar, para incorporar a la investigación en marketing la teoría y efectos de las emociones existen diversos aportes referenciales (Donovan y Rossiter, 1982; Bagozzi et al., 1999; Mattila y Wirtz, 2000; Bignè et al., 2005; Yüksel y Yüksel, 2007). Se toma el modelo de afecto PAD expuesto por Mehrabian y Russell (1974), la propuesta bidimensional de las emociones defendida por Russell (1980) y de la cual sólo tratamos la dimensión independiente de agrado, como en las investigaciones de De Rojas (2006) y Camarero (2008).

Finalmente, variables claves como la confianza y la satisfacción — que se encuentran en el enfoque de marketing de relaciones- nos ayudan a estudiar el comportamiento o respuesta emocional del visitante de cara a establecer relaciones con un destino turístico. Autores como Zeithalml et al. (1996), Bellman et al. (1999), Lacey (2007) y Lassala et al. (2010) enfatizan la importancia de medir las intenciones del comportamiento futuro de los consumidores para determinar su potencial de permanecer o de abandonar a la otra parte; es decir, quienes muestran unas actitudes favorables hacia la otra parte de la relación manifiestan una intención de compra en mayor grado.

Esta investigación tiene por objetivo presentar un marco teórico multidisciplinar para estudiar la influencia de la reputación y las emociones en la generación de confianza y, como resultado, conocer el grado de satisfacción de los turistas españoles que han viajado al destino turístico ecoarqueológico Mundo Maya-México ${ }^{1}$,

${ }^{1}$ La tipología ecoarqueológico es una nueva forma de hacer turismo, pues se enmarca en el contacto con la naturaleza y las culturas autóctonas locales, así como los vestigios arqueológicos de la región. Uno de los objetivos es impactar o alterar en menor medida el medio ambiente; de igual forma, comprender y respetar la flora y fauna propia del lugar, así como el modo de vivir de las culturas locales (Lara, 2006). 
después de la alerta sanitaria por la influenza $\mathrm{A} / \mathrm{H} 1 \mathrm{~N} 1$, que se registró a partir de los últimos días del mes de abril de 2009. Conjuntamente, este modelo desarrollado y propuesto concibe implícitamente dos enfoques: el cognitivo-afectivo de la satisfacción y el de factores afectivos procedente de la piscología ambiental. Las aportaciones de este trabajo a la literatura existente provienen de estudiar la díada turista/destino turístico desde un enfoque de naturaleza multidisciplinar que incluye aspectos económicos, psicológicos y relacionales. Este estudio, de naturaleza empírica, es sumamente relevante por el fenómeno planteado y potencializa el enfoque y teorías abordadas de forma conjunta porque se percibe en la literatura un análisis individualizado de cada uno de estos componentes.

Este estudio se ha estructurado del siguiente modo: después de haber hecho la presentación, profundizamos en los aspectos teóricos fundamentales que dan soporte a las teorías y al enfoque abordado en este trabajo; asimismo, como marcos de estudio de las relaciones del turista con un destino turístico se presentan la teoría de señales, las teorías de emociones y el enfoque de marketing de relaciones. Posteriormente, se formulan las hipótesis de trabajo y se propone un modelo causal explicando las relaciones de cada una de nuestras variables. En seguida, se hace referencia a la metodología empleada y detallamos el estudio empírico y sus resultados. Por último, en las conclusiones, se consideran las limitaciones del estudio, las líneas para futuras investigaciones y las implicaciones profesionales.

\section{Delimitación del ámbito de estudio y marco teórico}

\section{Teoría de señales: reputación}

Con relación a los aportes de la teoría de señales, la cual sienta sus bases en la economía de la información, se asume desde una perspectiva normativa que la información entre los distintos agentes económicos es imperfecta y asimétrica. Las señales en marketing son una actividad del marketing que proporciona la información más allá de la actividad en sí misma y revela más allá de lo inobservable. Estas señales se pueden enviar a los competidores, a los clientes, a los proveedores o a otros stakeholders (Herbig y Milewicz, 1996). Esta información desempeña un papel central en la toma de decisiones por parte de los consumidores en los mercados de competencia monopolística (Akerlof, 2002). Emanada de estas imperfecciones del mercado, Akerlof (1970) indica el efecto de desplazamiento en el contexto de una economía con información asimétrica debido a que los agentes con mayor 
suministro de información desplazan a los menos informados del mercado, y de tal situación el producto malo desplaza al producto bueno. Por ello, observamos que el consumidor toma decisiones basadas únicamente en la información de la cual dispone y a partir de las señales transmitidas por el vendedor, que además tiene el poder para decidir la información que suministra (Kirmani y Rao, 2000). Podemos concluir que lo esencial en este enfoque es el mercado porque estudia cómo el consumidor de manera racional toma decisiones ante las acciones de la empresa $\mathrm{o}$ vendedores.

Desde la perspectiva del enfoque psicológico, el consumidor tiende a confiar en las señales porque le transmiten calidad y no se molesta en la búsqueda de información excesiva (San Martín, 2003). Este enfoque se encarga del estudio de los consumidores y del proceso o conjunto de asociaciones por los cuales el consumidor responde a las acciones de la empresa o vendedor. Por lo tanto, las señales actúan como mecanismos transmisores de información a través de mensajes implícitos o explícitos transmitidos por individuos u organizaciones, los cuales poseen mayor información que un receptor con menor cantidad de ésta. Paralelamente a lo expuesto, en los trabajos de Bergen et al. (1992) y Kirmani y Rao (2000) retomamos que el objetivo de dicho enfoque es transmitir información concerniente a aspectos como la calidad, comportamiento, intenciones, valores o capacidades del emisor buscando distinguirse de sus competidores que carezcan de estos atributos.

Entre estos planteamientos realizados cabe destacar el papel que desempeña la reputación de marca como señal para el mercado (Kreps y Wilson, 1982; Chu y Chu, 1994; Erdem y Swait, 1998). Por nuestra parte, abordamos el estudio de la reputación de marca aplicado al caso de un destino turístico. Exponemos como justificación para nuestra investigación que la reputación de marca se torna como una variable clave, la cual es utilizada por el viajero para evaluar holísticamente un destino turístico durante su visita, pues es un hecho que un destino turístico sólido y competitivo se apoya en un símbolo que lo comunique, que lo identifique y que reúna los atributos del lugar. Autores como Obiol (2002) sostienen que sin marca turística puede existir un recurso turístico, pero será difícil construir un producto turístico homologable; por lo tanto, la marca es la portadora de dar vida al destino, producto o servicio turístico y, sobre todo, facilitar su venta. Finalmente, observamos que la reputación de marca del destino turístico contribuye a crear una ventaja competitiva si logramos introducir la percepción adecuada o deseada en la mente del turista e influir en su decisión de viaje y, muy posiblemente, en su intención de regreso como resultado de su satisfacción. 


\section{Las emociones y sus implicaciones en el turista}

Las emociones son respuestas provocadas por un estímulo específico, generalmente tienen la característica de ser intensas y al tener una mayor duración queda como recuerdo de la emoción en el pasado, es decir, éstas son almacenadas en la memoria y recobradas posteriormente durante la exposición de la experiencia (Cohen y Arení, 1991; Agarwal y Malhotra, 2005). Para fines de este estudio hablaremos de emociones justificadas por su naturaleza más intensa y de estímulos específicos; asimismo, se adopta un enfoque cognitivo, esto es, de experiencia emocional (Frijda, 1986; Bigné y Andreu, 2004). Como resultado, esta variable se manifiesta en una respuesta concreta a eventos particulares, pues son la vía para evaluar de forma subjetiva el afecto como estado anímico del individuo. En consecuencia, tenemos que las emociones activan y dirigen la conducta y nos inducen para acercarnos a un(os) producto(s) o alejarnos de él (ellos).

En añadidura, los sentimientos de los individuos pueden reflejarse en ciertas intenciones dependiendo de su estado emocional en el momento de tomar una decisión (Goossens, 2000); por tanto, las emociones regulan e influyen en el comportamiento e incluso lo organizan (Peter y Olson, 1999). Así, las emociones convierten las actitudes del turista en intenciones, generándole deseos, transformando sus percepciones, sus experiencias y permitiéndole establecer asociaciones con el destino turístico (Goossens, 2000). Es de esperar que los turistas que muestran actitudes favorables por el destino turístico manifiesten una mayor intención de compra. Es por ello que los turistas eligen un destino turístico esperando que éste les ofrezca un conjunto de beneficios a largo plazo de acuerdo con las emociones que les inspira el lugar.

\section{- El papel de las emociones: agrado}

En cuanto al estudio de la calidad ambiental en psicología y sus aportes para este estudio, nos lleva a comprender la perspectiva del consumidor o consumidores potenciales en un entorno dado a partir de dos contribuciones: 1) desde el criterio ambiental, donde se evalúa el entorno por medio de indicadores intangibles, por ejemplo, los indicadores de la calidad ambiental percibida por los consumidores; y 2) la parte psicológica, la cual nos provee de la información para conocer qué aspectos del entorno que rodean al sujeto poseen influencia en sus valoraciones $y$, por otra parte, que nos aporta el resultado de esta influencia. 
En esta perspectiva ambiental Real et al. (1996) exponen en su estudio la existencia de cuatro factores que interactúan en el proceso que realiza el individuo sobre la evaluación del entorno; estos componentes los establecen: 1) el que observa, 2) los medios por los cuales se evidencia el estimulo experimentado, 3) las estructuras de respuestas, y 4) las características físicas del entorno, las cuales están estrechamente relacionadas con los estímulos ambientales que tienen efecto en las personas. Es precisamente en este cuarto componente ambiental donde se potencializa una de las estructuras más usadas para medir las características de los estímulos emocionales de los consumidores en marketing, es decir, el modelo de afecto PAD (pleasure, arousal y dominance).

Existe un amplio acuerdo entre los investigadores respecto al carácter bidimensional de las emociones; los pioneros en la propuesta son Russell (1980) y Russell y Pratt (1980) y, sucesivamente, Donovan y Rossiter (1982), Ward y Russell (1981), Wirtz y Bateson (1999), Mattila y Wirtz (2000), Bigné et al. (2005), Yüksel y Yüksel (2007), Yüksel (2007) y Bigné et al. (2008). La literatura sobre emociones nos muestra que éstas pueden describirse en función de dos dimensiones principales. Dicha estructura consta de una configuración circular a la que suele designarse modelo circumplejo, la cual describe las interrelaciones entre las emociones (Plutchik, 1980). Por tal razón, Russell y Pratt (1980) defienden el fundamento de dos dimensiones independientes dentro de las emociones: la valencia agrado y la activación. La dimensión agrado es un sentimiento subjetivo de lo agradable o desagradable, haciendo referencia al nivel en el cual una persona se siente bien o mal (e.g., feliz-infeliz) en una determinada situación; y la dimensión activación como un estado subjetivo de sentimiento activado o desactivado (e.g., animado-decaído), refiriéndose a la extensión en la cual una persona se siente estimulada y activa.

Para nuestros fines estudiaremos solamente la dimensión de agrado de las emociones porque deseamos conocer los sentimientos del turista por un destino turístico como resultado de la experiencia de haber visitado el lugar; se considera la tipología que presenta el destino turístico, la cual va dirigida a preservar el conocimiento, creencias y tradiciones de una cultura ancestral y el respeto por el medio ambiente. Para ello, mediremos el agrado del visitante derivado del estímulo o los sentimientos que le inspira este destino turístico, como en las investigaciones de De Rojas (2006) y Camarero (2008), en las cuales se intentaba valorar el escaso conocimiento que se tiene sobre diferentes factores que se dan durante la visita a las actividades culturales y museísticas que generan emociones y satisfacción en el visitante a través de sus vivencias positivas. 


\section{Enfoque de marketing de relaciones}

A lo largo de la última década, numerosos autores han llegado a la conclusión de que lo central en el marketing son las relaciones. Estas relaciones son contactos entre dos o más personas, pero también se dan entre personas y objetos, símbolos y organizaciones (Gummesson, 1996). La teoría y la práctica del marketing de relaciones se han centrado en intercambios persistentes entre los compradores y los vendedores (Dwyer et al., 1987); por ello, las investigaciones de marketing de relaciones no deben analizar tan sólo los intercambios entre compradores y vendedores como situaciones simples o transacciones discretas, sino como relaciones continuas en el tiempo. Por lo anterior surge la necesidad de realizar un esfuerzo integrado por mantener y consolidar el intercambio con los clientes a través del tiempo.

De igual modo, en el área de marketing de servicios, Berry (1983, p. 25) manifiesta que el "marketing de relaciones consiste en atraer, mantener y -en las organizaciones de múltiples servicios- mejorar las relaciones con los clientes". En un estudio posterior, Berry y Parasuraman (1991, p. 133) proponen que "el marketing de relaciones se refiere a la atracción, al desarrollo, y al mantenimiento de las relaciones con los clientes". La clave consiste en ver la relación con cada cliente como un todo, no como series aisladas de transacciones no interrelacionadas. Por ello, el marketing de relaciones se basa en la continuidad, mientras que el enfoque transaccional enfatiza lo discreto. Se dice que desde una perspectiva de intercambio transaccional la relación con el cliente termina cuando se produce la venta; en tanto que al adoptar un enfoque de intercambio relacional con la venta comienza la relación con el cliente.

En el intercambio relacional los costos de cambio tienden a ser altos en contraposición a lo que sucede en el intercambio transaccional. De hecho, el cliente se compromete con la empresa y, en consecuencia, tiende a ser más fiel (Jackson, 1985). A razón de esto, el cliente se involucrará en la relación, pues así las partes se esforzarán con gran intensidad en ella (Stone y Mason, 1997). Es así que Berry (1995) pone énfasis en que para un determinado producto el marketing relacional puede ser apropiado para los consumidores propensos a la lealtad, y no para los que tienden a intercambios breves. Se dice que hay clientes transaccionales rentables, pero que no lo son de forma relacional, por eso, el valor de una parte se mejora aumentando las ventajas y/o reduciendo el sacrificio para la otra parte de la relación. Sin duda, esto mejorará la satisfacción y estimulará la continuidad entre las partes de la relación. 
En suma, para el ámbito que nos ocupa, el marketing de relaciones consiste en hacer inversiones para cimentar la confianza del turista a largo plazo; lo anterior a través del mantenimiento de buenas relaciones con los clientes, distribuidores, comerciantes, proveedores, operadores turísticos ${ }^{2}$ y las DMC (Destination Management Company $)^{3}$, entre otros stakeholders. Lo anterior por medio de la promesa y cumplimiento del suministro de alta calidad y del ofrecimiento de un buen servicio y precio justo a través del tiempo por los gestores del destino turístico.

\section{- La confianza en la relación del turista con el destino turístico}

En la literatura se percibe que la confianza ha estado considerada de muy diversas formas; por ejemplo, Wetzels et al. (1998) proponen que la confianza se define como la creencia de una parte en la cual sus necesidades serán satisfechas en el futuro por las acciones emprendidas por la otra parte. En este sentido, Ganesan (1994) considera que la confianza es una creencia, un sentimiento o expectativa con respecto a lo que se espera de la otra parte de la relación que procede de la pericia de ésta, de su fiabilidad y de su intencionalidad. Simultáneamente, Morgan y Hunt (1994) apuntan que la confianza existe cuando una parte cree en la confiabilidad y la integridad de la otra parte.

Considerando las ideas expuestas, entendemos como confianza la relación emocional que existe entre una de las partes de la relación, fiándose una de la otra a partir de que ésta mantenga una garantía de su buena reputación dentro de los servicios que ofrece de manera holística. Por tal efecto, destacamos la importancia de la confianza en el ámbito de los servicios, considerándola como un constructo unidimensional y abordada por escalas globales para su medición; así se ha constatado en diversos trabajos que nos aporta la literatura (Morgan y Hunt, 1994; Garbarino y Johnson, 1999; Hess y Story, 2005).

Finalmente, la confianza adquiere una importancia clave en situaciones en las que la información de la que dispone el individuo es parcial o incompleta (Hawes et

\footnotetext{
${ }^{2}$ Un operador turístico es la empresa que ofrece productos o servicios turísticos, generalmente contratados por él, e integrados por más de uno de los siguientes ítems: transporte, hotelería y excursiones. Puede ser operador mayorista si trabaja exclusivamente con agencias de viajes o mayorista/minorista en caso de ampliar su oferta al público de forma general.

${ }^{3}$ Un Destination Management Company (DMC) es un término usado para una empresa de servicios a profesionales, la cual ofrece gran conocimiento del lugar, experiencia y recursos para el diseño y ejecución de eventos, actividades, excursiones, transporte, meetings y congresos.
} 
al., 1989). En este tipo de situaciones, la confianza actúa como un recurso capaz de reducir el nivel de asimetría de información existente (Moorman et al., 1993; Doney y Cannon, 1997) y facilita la adopción de decisiones en situaciones de riesgo (Mayer et al., 1995) disminuyendo así el grado de complejidad asociado al proceso de toma de decisiones (Barber, 1983). Además, Morgan y Hunt (1994) nos demuestran empíricamente el hecho de que la confianza provee de una nula propensión al abandono; es decir, la propensión percibida de que la otra parte concluya la relación posteriormente.

\section{- La satisfacción en la relación del turista con el destino turístico}

A pesar de que no existe un claro consenso al momento de discernir cuáles son las variables determinantes de la satisfacción, encontramos investigaciones como la de Oliver (1980) que asumen un enfoque cognitivo, el cual esboza la satisfacción a partir de un proceso de comparación que realiza el consumidor de la calidad percibida frente a sus expectativas. Precisamente, la confirmación/disconfirmación de la satisfacción es el resultado de un proceso de comparación; la conformidad se obtiene si el rendimiento del producto o servicio percibido satisfacen exactamente las expectativas, mientras que la disconformidad resulta de una falta de satisfacer exactamente estas expectativas. En concreto, la disconfirmación positiva ocurre si el rendimiento del producto o servicio excede a las expectativas del cliente, mientras que la disconfirmación negativa ocurre cuando el producto o servicio no resulta según lo esperado por éste.

Sin embargo, el enfoque cognitivo, como lo demuestran ciertos estudios, presenta limitaciones al momento de explicar las decisiones de compra y satisfacción de los consumidores (Bagozzi, 1997; Cronin et al., 2000). Ante esta situación, la literatura nos demuestra que los investigadores de marketing conciben a la satisfacción mediante dos componentes básicos: el cognitivo desde la óptica de las teorías confirmación/disconfirmación y el afectivo desde la parte de emociones (Oliver, 1993; Wirtz y Bateson, 1999). Por su parte, el componente emocional puede ser definido como el grado por el cual un consumidor en posesión o uso de un servicio despierta sentimientos positivos como interés, entretenimiento, sorpresa, ira o vergüenza (Cronin et al., 2000).

Para efectos del presente estudio, la satisfacción del turista se concibe a través de la experiencia que ha vivido durante su visita al lugar, la cual se obtiene cuando el viajero realiza evaluaciones cognitivas-afectivas de las distintas características 
del destino turístico, superando o no sus expectativas, así como estimulando respuestas de comportamiento de conducta del visitante y la reacción por parte de éste a repetir su visita o recomendar el lugar (e.g., comunicación boca-oído); esto lo podemos observar en el trabajo de Kozak (2001). Por otra parte, existe una relación entre la satisfacción y la intención total de regresar al destino como resultado de una discofirmación positiva de las expectativas del visitante, ya que el viajero desea una experiencia integral que contenga ocio, cultura, educación e interacción social como preludio de su satisfacción (De Rojas y Camarero, 2008).

\section{Formulación de las hipótesis y modelo propuesto}

\section{Antecedentes de la reputación y las emociones}

El enfoque psicológico, como hemos apuntado, se encarga del estudio de los consumidores y del proceso o conjunto de asociaciones a partir de los cuales el consumidor responde a las acciones de la empresa o vendedor. Desde esta óptica, las señales actúan como mecanismos transmisores de información (San Martín, 2003). Por ello, es de esperar que una reputación positiva y fuerte reduzca el riesgo de compra de los clientes potenciales. Esta reducción del riesgo surge del aumento de la seguridad porque hay una buena reputación en el mercado. Es también probable que de esa buena reputación deriven sentimientos positivos del consumidor (Herbig y Milewicz, 1993; Peter y Olson, 1999).

Por su parte, las emociones reflejarán dos dimensiones independientes: el agrado y la activación (Russell y Pratt, 1980; Bigné y Andreu, 2004; Yüksel y Yüksel, 2007). El agrado se refiere al nivel en el que una persona se siente bien, feliz o inmerso en un entorno, mientras que la activación se refiere a la medida en que un individuo requiere para sentirse estimulado y activo. No obstante, otros autores han tratado sólo la dimensión de agrado de las emociones (De Rojas y Camarero, 2006, 2008). Al igual que en estos trabajos, pensamos que la dimensión de activación resulta de poca transcendencia para estimular las actividades de los visitantes, pues en un destino de la tipología ecoarqueológico los objetivos son fundamentalmente despertar el interés de los visitantes y el aumento de sus conocimientos sobre la cultura, tradiciones, así como el respeto por el medio ambiente del lugar en el cual el viajero experimentará la dimensión de agrado o placer de las emociones. Con relación a lo anteriormente expuesto, la reputación positiva de un destino turístico estimula el desarrollo de emociones positivas en el visitante, en su 
dimensión independiente de agrado, en lo que consideramos una hipótesis nueva, pues no existen trabajos que la hayan tratado anteriormente. De aquí se deriva el siguiente supuesto:

H1: La reputación del destino turístico influye positivamente en las emociones (agrado) que siente el turista por ese destino turístico.

\section{Antecedentes de la confianza, reputación y emociones}

La literatura ha encontrado en la reputación el factor dominante para crear confianza en las organizaciones, entre los consumidores y en las relaciones de ambas partes concebidas en el intercambio tradicional de marketing (Ganesan, 1994; Doney y Cannon, 1997), así como en el contexto de comercialización de los destinos turísticos (Cristopher et al., 1991). Mitchell y Vincent-Wayne (1999) explican que la reputación actúa como un estímulo de las percepciones cognitivas de calidad generando confianza. Del mismo modo, Moorman et al. (1993) realizan comentarios similares sobre la reputación, pues es un indicador de la confiabilidad. Por lo tanto, desde esta perspectiva, la reputación sirve como un medio para reducir incertidumbre y generar una sensación de confianza entre los consumidores para atraer las transacciones hacia la organización. En ciertas condiciones, el desarrollo acertado de la reputación de un destino turístico y de la confianza puede conducir a la formación de vínculos personales y funcionales entre el visitante y el destino turístico. De acuerdo con estas ideas expuestas se formula la siguiente hipótesis:

H2: La reputación de un destino turístico influye positivamente en la confianza que siente el turista por ese destino turístico.

El marketing desarrolla y explica las emociones como respuestas afectivas del consumidor exponiendo las valoraciones cognoscitivas de acontecimientos y pensamientos (Oliver, 1997; Peter y Olson, 1999; Bagozzi et al., 1999). Es un hecho que la confianza, como se señaló, nos provee de seguridad emocional porque lleva a una de las partes de la relación a creer que la otra parte actuará con responsabilidad; esa seguridad será mayor cuanto más positivas sean las emociones que el destino turístico ofrezca al consumidor. Las emociones como estímulos de respuestas hacia la confianza del turista serán medidas a través del modelo bidimensional de Russell (1980); sin embargo, en nuestro estudio sólo abordamos una versión reducida del modelo de afecto PAD, la dimensión independiente de agrado; esta configuración ha sido utilizada para modelizar las reacciones emocionales del con- 
sumidor durante su vivencia en entornos de ocio y placer (e.g., De Rojas y Camarero, 2006, 2008; Yüksel, 2007). Por lo anterior, las emociones positivas que siente el visitante por un lugar influirán positivamente en su confianza; estos argumentos nos llevan a formular la siguiente hipótesis:

H3: Las emociones (agrado) que siente el turista hacia un destino turístico influyen positivamente en la confianza de él/ella por ese destino turístico.

\section{Antecedentes de la satisfacción, confianza y emociones}

Por lo que respecta al entorno de las vivencias del turista, se destaca la necesidad de concebir conceptos cognitivos y afectivos para revelar la satisfacción del visitante, sus intenciones y comportamientos (Mano y Oliver, 1993; Dubé y Menon, 2000; Zins, 2001). Además, existen diferentes estudios que señalan la relación existente entre el agrado experimentado durante la experiencia del consumo y la satisfacción obtenida después del consumo (Mano y Oliver, 1993; Wirtz y Bateson, 1999). Autores como Oliver (1993); Oliver et al. (1997); Wirtz y Bateson (1999); Bigné y Andreu (2004) y De Rojas y Camarero (2008) nos revelan en sus investigaciones empíricas que las emociones (agrado) han sido corroboradas de manera notable presentando una influencia directa y positiva sobre la satisfacción del visitante. Tomando como referencia el modelo bidimensional de las emociones propuesto por Russell (1980), y de manera abreviada por medio de la dimensión independiente de agrado, formulamos el hecho de la relación positiva entre el agrado sobre la satisfacción y procedemos a realizar la siguiente hipótesis:

H4: Las emociones (agrado) que siente el turista hacia un destino turístico se ven influidas positivamente en la satisfacción del mismo.

Por otra parte, como hemos observado, la confianza se relaciona con diversas variables y ayuda a disminuir el comportamiento oportunista que puede existir en cualquier tipo de relación. En este contexto, el grado de satisfacción es un antecedente del intercambio, lo que lleva a esperar que la otra parte no efectúe acciones oportunistas. La confianza es un referente de la intensidad de la relación, ya que los consumidores intentan disminuir el riesgo percibido en la compra de manera más eficiente que otros elementos existentes (Doney y Cannon, 1997; Lacey, 2007). Por tanto, a través de esta disminución del riesgo percibido se genera la repetición de compra, ya sea de la misma marca o comprando con el mismo proveedor del 
servicio con el cual se está satisfecho. Así, la confianza es una evaluación agregada a un más alto nivel que la satisfacción (Ganesan, 1994). En definitiva, a mayor confianza con la otra parte de la relación, mayor expectativa de que las necesidades serán satisfechas para la otra parte (Fernández y Martín, 2006). En consecuencia, la hipótesis de trabajo que hace referencia a la relación entre la confianza y la satisfacción quedaría de la siguiente manera:

H4: La confianza que siente el turista hacia un destino turístico se ve influida positivamente en la satisfacción del mismo.

Gráfica 1

\section{Modelo multidisciplinar propuesto}

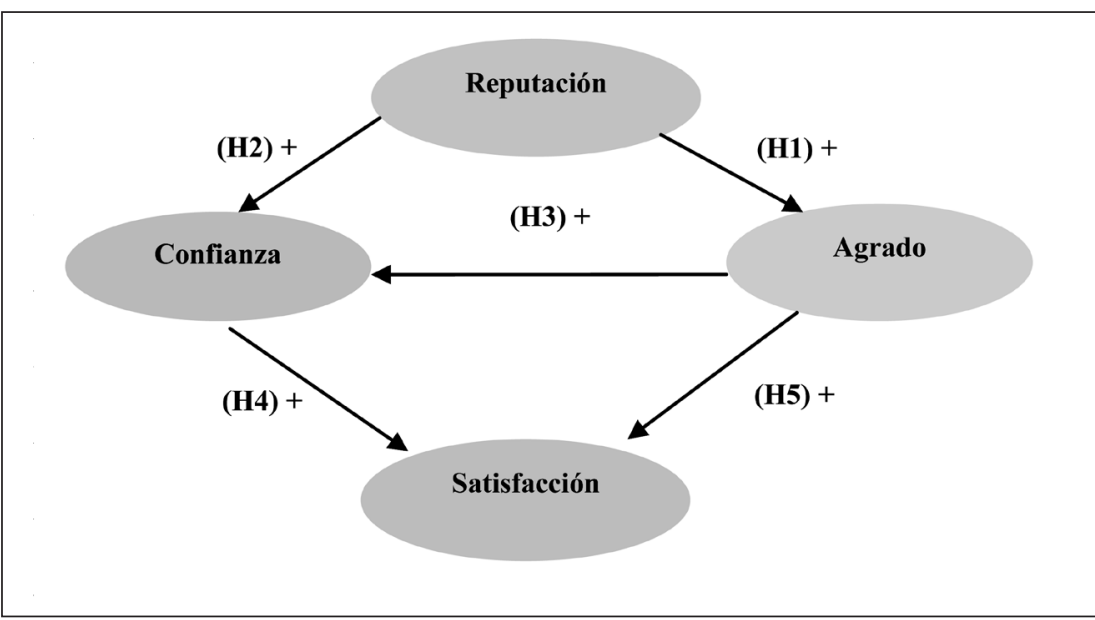

\section{Metodología}

\section{Diseño de la muestra y ámbito de estudio}

En esta sección detallamos la metodología de investigación que hemos utilizado para el análisis empírico del modelo. Hemos decidido situarnos en el sector turístico por su importancia en las economías de las regiones, por el alto grado de competitividad y por la característica propia del producto turístico: su intangibilidad; esto genera gran incertidumbre en el viajero que tiene que elegir entre la mejor alternativa para obtener su satisfacción durante su visita a un lugar. El destino turístico que hemos elegido para llevar a cabo el estudio es de la tipología ecoar- 
queológico, en el cual se encuentra enmarcado Mundo Maya México, integrado por cinco estados del sureste mexicano: Tabasco, Chiapas, Campeche, Yucatán y Quintana Roo.

Se ha recogido la información a través de encuestas personales que han sido aplicadas en las zonas arqueológicas localizadas en los diferentes lugares que integran el destino en su totalidad con el permiso y colaboración del encargado en cada caso. Hemos recolectado información a través de un cuestionario minuciosamente estructurado para ser aplicado a españoles que permanecen en el destino turístico de visita. Concretamente, se han elegido las zonas arqueológicas para recoger la información, encuestar a españoles de diferentes características y situar a todos los visitantes en un contexto similar de comportamiento y experiencia de viaje en el sureste mexicano. El periodo de realización de las encuestas fue durante los meses de julio a septiembre de 2010; se enviaron 1200 encuestas para aplicarse, de ellas se devolvieron 618 encuestas válidas. La tasa de respuesta fue del $51.5 \%$ (618/1200), valor que hemos considerado aceptable. El cuadro 1 recoge la ficha técnica del estudio.

\section{Cuadro 1}

\section{Ficha técnica del estudio}

\begin{tabular}{l|l}
\hline Características & Encuesta \\
\hline Área geográfica & -Mundo Maya (México) \\
\hline Tamaño del universo & $\begin{array}{l}\text {-Zonas arqueológicas localizadas en las diferentes provincias que } \\
\text { componen el destino turístico en su totalidad }\end{array}$ \\
\hline Tamaño muestral & $\begin{array}{l}\text {-Se recibieron 618 encuestas válidas de un total de 1200 encuestas } \\
\text { hechas (tasa de respuesta }=51.5 \%)\end{array}$ \\
\hline Error muestral & $\begin{array}{l}3.9 \%(\text { para el caso más desfavorable y un nivel de confianza del } \\
95 \%: \mathrm{p}=\mathrm{q}=0.5)\end{array}$ \\
\hline Diseño muestral & $\begin{array}{l}\text {-La información fue recogida mediante encuesta personal a turistas } \\
\text { que se encontraban de visita en el destino turístico }\end{array}$ \\
\hline Periodo & -Junio a septiembre de 2010 \\
\hline
\end{tabular}

A las personas de la muestra se les proporcionó aleatoriamente la encuesta durante su visita a las zonas arqueológicas y se les pidió su colaboración para contestar las preguntas referentes a valorar la reputación, la confianza, las emociones y la satisfacción durante su visita a Mundo Maya-México. Las dos preguntas introductorias del cuestionario manifestaron ciertos hallazgos; por ello, es importante mencionar que pese a las preferencias de los españoles por México como destino turístico existen muy pocas personas que conocen los lugares del Mundo MayaMéxico. Así, hemos obtenido que los estados más conocidos por los españoles de 
la muestra fueron: Quintana Roo con 77\% y Yucatán con 66.6\%; mientras que los menos conocidos por los encuestados fueron: Chiapas con 33\%, Campeche con $21.0 \%$ y Tabasco $16.8 \%$, este último se sitúa como el que menos frecuencia de conocimiento presenta en los españoles de la muestra. Aunque todos estos lugares integran el destino en su totalidad, sólo $27.8 \%$ de las personas de la muestra manifestaron su conocimiento de Mundo Maya-México. Una razón de estos resultados puede ser la alta reputación de notoriedad y de gestión alcanzada por la Riviera Maya en España, lo que ocasiona que muchos turistas lo confundan con Mundo Maya-México, así como se dé la confusión del lugar donde se encuentra situado. En contraste, podemos observar la frecuencia de españoles que han estado de vacaciones en los diferentes destinos que componen esta marca turística: se observa que el $12.4 \%$ que han realizado circuito en varios lugares que forman el destino, el 61.6\% ha permanecido en Quintana Roo, en Yucatán 13.1\%, en Chiapas 8.4\%; estos tres estados son los que presentan mayor frecuencia de visitas a diferencia de Campeche con $1.9 \%$ y Tabasco con $2.4 \%$. La estructura de la muestra se presenta en el cuadro 2.

\section{Cuadro 2}

\section{Características sociodemográficas de la muestra}

\begin{tabular}{l|c|c|l|c|c}
\hline Estructura del hogar & Frecuencia & $\mathbf{( \% )}$ & \multicolumn{1}{|c|}{ Sexo } & Frecuencia & $\mathbf{( \% )}$ \\
\hline $\begin{array}{l}\text { Viven de manera } \\
\text { unipersonal }\end{array}$ & 186 & $30.0 \%$ & Hombres & 352 & $56.9 \%$ \\
\hline Pareja sin hijos & 285 & $46.0 \%$ & Mujeres & 266 & $43.0 \%$ \\
\hline Pareja con hijos & 135 & $21.8 \%$ & Edad & & \\
\hline Uno o más hijos & 12 & $1.9 \%$ & Menos de 20 años & 14 & $2.3 \%$ \\
\hline Nivel de estudios & & & Entre 21 y 30 años & 306 & $49.4 \%$ \\
\hline Carece de estudios & 5 & $0.8 \%$ & Entre 31 y 40 años & 199 & $32.1 \%$ \\
\hline Estudios primarios & 38 & $6.1 \%$ & Entre 41 y 50 años & 67 & $10.8 \%$ \\
\hline Estudios medios & 111 & $17.9 \%$ & Entre 51 y 60 años & 30 & $4.8 \%$ \\
\hline Estudios superiores & 464 & $75.0 \%$ & Más de 60 años & 2 & $0.3 \%$ \\
\hline Ocupación & & & $\begin{array}{l}\text { Renta mensual neta } \\
\text { del hogar }\end{array}$ & & \\
\hline $\begin{array}{l}\text { Trabajador a por cuenta } \\
\text { ajena }\end{array}$ & 238 & $38.4 \%$ & $\begin{array}{l}\text { Perciben menos de } \\
600 €\end{array}$ & 94 & $15.2 \%$ \\
\hline Empresarios & 66 & $13.7 \%$ & Entre 601-900 € & 73 & $11.8 \%$ \\
\hline Autónomo & 85 & $12.6 \%$ & Entre 901-1200 $€$ & 77 & $12.4 \%$ \\
\hline Jubilado & 27 & $1.9 \%$ & Entre 1201-1500 $€$ & 63 & $10.2 \%$ \\
\hline Funcionario & 78 & $10.7 \%$ & Entre 1501-1800 $€$ & 49 & $7.9 \%$ \\
\hline Estudiante & 100 & $4.4 \%$ & Entre 1801-2400 $€$ & 149 & $24.1 \%$ \\
\hline Ama de casa & 12 & $16.2 \%$ & Entre 2401-3000 $€$ & 60 & $9.7 \%$ \\
\hline Desempleado & 12 & $1.9 \%$ & Más de 3000 $€$ & 53 & $8.6 \%$ \\
\hline Nota: $\mathrm{n}=618$ & & & & & \\
\hline
\end{tabular}




\section{Medición de variables y cuestionario}

Para el desarrollo de las escalas de medida de las variables empleadas y su cuantificación se emplearon diversas investigaciones empíricas que proporciona la literatura en diversos campos como la teoría de señales, la teoría de emociones en marketing y el enfoque de marketing de relaciones. En concreto, se adaptaron escalas previamente utilizadas en la literatura, las cuales reflejan una validez aparente y de contenido aceptable para cada constructo tras la recomendación de los autores (Zaichkowsky, 1985). Así, el cuestionario utilizado en este trabajo se estructuró en tres apartados, en la primera sección, se recogieron las preguntas introductorias del cuestionario; en el segundo apartado se observan las preguntas a partir de ítems adaptados para obtener la información sobre las diferentes variables abordadas (reputación, emociones -agrado-, confianza y satisfacción) como resultado de su visita al destino turístico y, por último, se presentan los datos del encuestado.

Análogamente, para la reputación (9 ítems) se consideraron los trabajos de Doney y Cannon (1997), Hall (1993), Fombrun et al. (2000), Bennet y Gabriel (2001) y Bart et al. (2005). Las emociones (agrado) (6 ítems) se midieron con base en la escala de Russell (1980), proveniente de la psicología ambiental. Por lo que concerniente a la confianza (8 ítems), se tomaron trabajos ya testados por Selnes (1988), Ganesan (1994), Evans y Laskin (1994), Doney y Cannon (1997), Wetzels et al. (1998), Ruyter y Wetzels (1999), San Martín (2003) y Bart et al. (2005). En relación con la variable satisfacción (7 ítems), se recurrió a trabajos comprobados previamente por Macintosh y Lockshin (1997), Wetzels et al. (1998), Garbarino y Johnson (1999), Lemon et al. (2002), Bigné y Andreu (2004) y Hess y Story (2005). Finalmente, en cuanto a las características personales del encuestado (sexo, estructura del hogar, edad, nivel de estudios, profesión y renta mensual neta del hogar) las escalas que se utilizaron son de elaboración propia, las cuales fueron adaptadas al caso de los viajes. Los ítems que se utilizaron para medir la reputación, la confianza y la satisfacción aparecen medidos a través de escalas tipo Likert de cinco posiciones (desde totalmente en desacuerdo a totalmente de acuerdo con la proposición formulada en cada caso); cabe aclarar que para las emociones en su dimensión independiente de agrado se presento una escala de adjetivos bipolares de cinco posiciones; por último, las variables que encierran las características personales del encuestado se codificaron de manera 
distinta (sexo, estructura del hogar, edad, nivel de estudios, profesión y renta mensual neta del hogar ${ }^{4}$.

\section{Análisis de fiabilidad y dimensionalidad}

En esta etapa hemos recurrido a la modelización mediante ecuaciones estructurales para la validación de las escalas de manera individual y para estimar el modelo global en su fase exploratoria. Por esta razón, se lleva a cabo un estudio de las variables incluidas en el modelo teórico propuesto a través de un análisis factorial con el programa estadístico SPSS 17.0, cuyos resultados avalan la definición de las variables propuestas. Los resultados del proceso de validación indican un correcto planteamiento de las escalas de medición propuestas con elevados niveles de fiabilidad, dados por los coeficientes alpha de Cronbach y de fiabilidad compuesto superiores a 0.7 (Bagozzi y Yi, 1988); igualmente, se comprueba que la correlación ítem total, donde se mide la correlación de cada ítem con la suma del resto de ítems de la escala, es superior al mínimo de 0.3 establecido por Nurosis (1993). También se ha considerado la validez convergente de los coeficientes estandarizados significativos y superiores a 0.5 (Steenkamp y Van Trip, 1991).

Para atestiguar la adecuada utilización de las escalas que nos han servido para medir las variables del modelo se realizó un análisis univariante y bivariante; tras verificar que no existían anomalías significativas en los datos se depuraron las escalas iniciales a través de un análisis factorial (análisis de ejes principales con rotación varimax), el cual nos permitió elegir los ítemes que tienen una carga factorial alta considerando la recomendación de los autores (Sanzo et al., 2003). Para ello, la extracción de factores se basó en la existencia de autovalores superiores a la unidad, por eso se requería de cada factor cargas superiores a 0.5 y que la varianza explicada por cada factor extraído fuera significativa. Este análisis nos arroja como resultado un agrupamiento de las variables en los siguientes factores:

\footnotetext{
${ }^{4}$ La codificación de estas cinco variables fue de la siguiente manera: para la variable: sexo: $1=$ hombre y $2=$ mujer; para la variable estructura del hogar se establecieron cuatro categorías: $1=$ unipersonal, $2=$ pareja sin hijos, $3=$ pareja con hijos y $4=$ uno más hijos; para la variable edad, se dieron seis categorías: $1=$ menos de 20 años, $2=$ 21-30 años, 3= 31-40 años, 4= 41-50 años, 5= 51-60 años, 6= más de 60 años; para la variable nivel de estudios, cuatro categorías: $1=$ sin estudios, $2=$ estudios primarios, $3=$ estudios medios, $4=$ estudios superiores; en la variable profesión, ocho categorías: $1=$ trabajador /a por cta. ajena, $2=$ empresario (a), 3= autónomo, 4= jubilado (a), 5= funcionario (a), $6=$ estudiante, $7=$ ama de casa, $8=$ desempleado (a); finalmente para la variable renta mensual: $1=$ menos de $600 €, 2=601-900 €, 3=901-1200 €, 4=1201-1500 €, 5=1501-1800 €, 6=1801-2400 €$, $7=2401-3000 €, 8=$ más de $3000 €$.
} 
1) para la reputación se obtuvo un factor, 2) con respecto a la emoción (agrado) se tuvo un factor, 3 ) en cuanto a la confianza se obtuvo un factor y 4) en cuanto a la satisfacción también hubo un solo factor (ver cuadro 3).

\section{Cuadro 3}

Resultados del análisis factorial exploratorio

\begin{tabular}{|c|c|c|c|c|c|}
\hline Variables & & Indicadores de los ítemes & $\begin{array}{c}\text { Peso de } \\
\text { cada } \\
\text { variable }\end{array}$ & $\begin{array}{c}\% \\
\text { Información } \\
\text { explicada }\end{array}$ & $\begin{array}{c}\% \\
\text { Información } \\
\text { acumulada }\end{array}$ \\
\hline \multirow{9}{*}{$\begin{array}{l}\text { Factor 1: } \\
\text { Reputación }\end{array}$} & V9 & Creencia en buena gestión & 0.805 & \multirow{9}{*}{60,404} & \multirow{9}{*}{60,404} \\
\hline & V10 & Representa calidad & 0.716 & & \\
\hline & V11 & Futuro a largo plazo & 0.565 & & \\
\hline & V12 & Ambientalmente responsable & 0.890 & & \\
\hline & V13 & $\begin{array}{l}\text { Creencia de la innovación } \\
\text { del lugar }\end{array}$ & 0.722 & & \\
\hline & V14 & $\begin{array}{l}\text { Utiliza recursos de forma } \\
\text { inteligente }\end{array}$ & 0.992 & & \\
\hline & V15 & $\begin{array}{l}\text { Mención en medios de } \\
\text { comunicación }\end{array}$ & 0.813 & & \\
\hline & V16 & $\begin{array}{l}\text { Familiarizado con lugares } \\
\text { similares }\end{array}$ & 0.557 & & \\
\hline & V17 & Buena reputación & 0.527 & & \\
\hline \multirow{6}{*}{$\begin{array}{l}\text { Factor 2: } \\
\text { Emoción } \\
\text { (agrado) }\end{array}$} & V18 & Feliz /infeliz & 0.574 & \multirow{6}{*}{72.194} & \multirow{6}{*}{72.194} \\
\hline & V19 & Contento/Enfadado & 0.949 & & \\
\hline & V20 & Encantado/Descontento & 0.901 & & \\
\hline & V21 & Alegre/Triste & 0.925 & & \\
\hline & V22 & Ilusionado/Desilusionado & 0.921 & & \\
\hline & V23 & Entretenido/Aburrido & 0.979 & & \\
\hline \multirow{8}{*}{$\begin{array}{l}\text { Factor 3: } \\
\text { Confianza }\end{array}$} & V24 & $\begin{array}{l}\text { Confianza en la competencia } \\
\text { profesional }\end{array}$ & 0.799 & \multirow{8}{*}{57.487} & \multirow{8}{*}{57.487} \\
\hline & V25 & $\begin{array}{l}\text { Creencia en excelentes } \\
\text { recursos técnicos }\end{array}$ & 0.974 & & \\
\hline & V26 & $\begin{array}{l}\text { Experiencia en la } \\
\text { comercialización }\end{array}$ & 0.720 & & \\
\hline & V27 & Creencia cumple sus promesas & 0.625 & & \\
\hline & $\mathrm{V} 28$ & Creencia conoce a sus clientes & 0.961 & & \\
\hline & V29 & Información detallada & 0.798 & & \\
\hline & $\mathrm{V} 30$ & Satisfacción hacia el cliente & 0.771 & & \\
\hline & V31 & $\begin{array}{l}\text { Características acordes a mis } \\
\text { gustos y preferencias }\end{array}$ & 0.761 & & \\
\hline \multirow{7}{*}{$\begin{array}{l}\text { Factor 4: } \\
\text { Satisfacción }\end{array}$} & V32 & Satisfacción con la estancia & 0.508 & \multirow{7}{*}{71.431} & \multirow{7}{*}{71.431} \\
\hline & V33 & Cumplimiento de expectativas & 0.601 & & \\
\hline & V34 & Satisfecho con el trato recibido & 0.671 & & \\
\hline & V35 & Acertada visita al lugar & 0.668 & & \\
\hline & V36 & $\begin{array}{l}\text { Entre los mejores lugares } \\
\text { visitados }\end{array}$ & 0.853 & & \\
\hline & V37 & He disfrutado el lugar & 0.611 & & \\
\hline & V38 & No me arrepiento de la visita & 0.577 & & \\
\hline
\end{tabular}


Asimismo, se evidencia la validez de contenido de la reputación, así como su fiabilidad, medido con el coeficiente alfa de Cronbach $(\alpha=0.849)$. En tanto para la emoción (agrado), se soporta la validez de contenido, lo que dio como resultado que la fiabilidad del coeficiente fuera alta $(\alpha=0.908)$; por su parte, la confianza ha obtenido un alfa de Cronbach fuerte $(\alpha=0.888)$; por último, en lo que concierne al constructo de la satisfacción ha resultado una fiabilidad robusta medida por el alpha de Cronbach $(\alpha=0.933)$. Finalmente, en el análisis factorial realizado, se apunta la existencia de los factores y variables que habíamos considerado.

\section{Análisis confirmatorio de dimensionaldad}

En esta fase, pese a que algunas de las escalas propuestas ya habían sido probadas en la literatura, fueron sometidas todas a un proceso de validación utilizando un análisis factorial. Seguidamente, para el conjunto de variables estudiadas se hizo un análisis factorial confirmatorio con el objetivo de comprobar la validez convergente y discriminante; se depuraron para simplificarlas con lo que se obtuvo las definitivas con la ayuda del programa estadístico LISREL 8.80. Hemos realizado un Path Análisis; este tipo de análisis factorial nos permitió determinar el grado de validez de cada escala, un concepto más amplio que el de fiabilidad.

Resultados del análisis factorial confirmatorio:

$\mathrm{X}^{2}=(399) 4641.747(\mathrm{p}=0.0) ; \mathrm{NFI}=0.889 ; \mathrm{CFI}=0.897 ; \mathrm{IFI}=0.897 ; \mathrm{RMR}=0.0921 ; \mathrm{GFI}=0.671$

En una segunda etapa de este análisis confirmatorio las medidas utilizadas para juzgar la procedencia de la eliminación de ítemes será el valor del estimador lambda o carga factorial $(\mid=>0.5)$, el del estadístico "t Student" debiendo ser mayor al valor crítico recomendado, lo que indica que se cumple este tipo de validez ( $\mathrm{t}=$ $>1.96$ ) correspondiente y el del coeficiente $\mathrm{R}^{2}$, mientras que para reespecificar el modelo cuando ha sido necesario se utilizaron las siguientes medidas de bondad del ajuste: 1) el valor de la Chi-cuadrado ( $\mathrm{p}=0.0) ; 2$ ) el índice de bondad del ajuste ( GFI= 0.966, Goodness of Fit Index ), como medida de bondad del ajuste absoluto - una medida de bondad del ajuste incremental; 3) el índice de bondad del ajuste comparativo (CFI=0.954, Comparative Fit Index); 4) el índice de ajuste normado (NFI $=0.953$, Normed Fit Index); 5) el índice de raíz cuadrada media residual $(R M R=0.0453$, Root Mean Square Residual) y 6) el índice de ajuste incremental $(I F I=0.954$, Incremental Fix Index). Con estas medidas trataremos de seguir la recomendación de los autores en cuanto a tomar diferentes tipos de medidas del 
ajuste con el objetivo de evitar los inconvenientes de cada una de ellas (Mackenzie, 2001). Para que exista un buen ajuste en los índices de CFI, IFI, NFI y GFI es favorable un acercamiento a 0.90 — cuanto mayor sea el índice, mejor ajustey para el índice RMR es favorable un valor menor a 0.09; por tanto, se apuntan los valores de la bondad de ajuste, la cual ha resultado buena a los valores críticos recomendados. Los resultados del análisis factorial confirmatorio y del análisis factorial confirmatorio reespecificado y ajustado se encuentran en el umbral deseable tras haber eliminado oportunamente determinadas variables del modelo V11, V12, V15 y V16, ya que sus cargas factoriales eran no significativas o inferiores (véase cuadro 4).

Resultados del análisis factorial confirmatorio ajustado:

$\mathrm{X}^{2}=(1) 45.626(\mathrm{p}=0.0) ; \mathrm{NFI}=0.953 ; \mathrm{CFI}=0.954 ; \mathrm{IFI}=0.954 ; \mathrm{RMR}=0.0453 ; \mathrm{GFI}=0.966$

Para la estimación del modelo global, como hemos comentado en párrafos anteriores, se realizó un análisis path de manera global para todo el modelo, considerando los factores de medida previamente estimado, tras el proceso de depuración de cada escala. Así, se observa que la bondad del ajuste del modelo es aceptable. Tras comprobar que los valores obtenidos en los índices de este modelo estructural confirmaban nuestro planteamiento, hemos procedido al contraste de las hipótesis establecidas. Por otra parte, confirmamos que el $\mathrm{R}^{2}$ de las variables latentes es superior a 0.1 antes de aceptar o rechazar las hipótesis propuestas. En la gráfica 2 se muestran los resultados obtenidos. Por consiguiente, la matriz de correlaciones entre las variables latentes nos indica que las variables están correlacionadas, sin embargo, son variables diferentes. No obstante, para comprobar la validez discriminante entre las variables latentes, se estimó un modelo confirmatorio de las variables latentes en conjunto, fijando a 1 las correlaciones y el resultado. En cuanto a las medidas de bondad del ajuste, aún observando que la correlación entre las variables no llega a ser 1 , sus valores resultan aceptables (véase cuadro 5). 
Cuadro 4

Resultados del análisis factorial confirmatorio ajustado

\begin{tabular}{|c|c|c|c|c|c|c|}
\hline \multirow{2}{*}{$\begin{array}{l}\text { Variable } \\
\text { latente }\end{array}$} & & \multirow{2}{*}{ Variable de medida } & \multicolumn{2}{|c|}{ Coeficientes lambda } & \multirow{2}{*}{$\begin{array}{c}\text { Varianza de } \\
\text { los errores de } \\
\text { medida }\end{array}$} & \multirow{2}{*}{$\mathbf{R}^{2}$} \\
\hline & & & lambda & $\mathbf{t}$ & & \\
\hline \multirow{9}{*}{ Reputación } & V9 & Creencia en buena gestión & 1.000 & 15.861 & 0.546 & 0.454 \\
\hline & V10 & Representa calidad & 1.195 & 17.436 & 0.353 & 0.647 \\
\hline & V11 & Futuro a largo plazo & \multicolumn{4}{|c|}{ Eliminada } \\
\hline & $\mathrm{V} 12$ & Ambientalmente responsable & \multicolumn{4}{|c|}{ Eliminada } \\
\hline & V13 & $\begin{array}{l}\text { Creencia de la innovación } \\
\text { del lugar }\end{array}$ & 1.036 & 15.442 & 0.513 & 0.487 \\
\hline & V14 & $\begin{array}{l}\text { Utiliza recursos de forma } \\
\text { inteligente }\end{array}$ & 1.150 & 16.897 & 0.400 & 0.600 \\
\hline & V15 & $\begin{array}{l}\text { Mención en medios de } \\
\text { comunicación }\end{array}$ & \multicolumn{4}{|c|}{ Eliminada } \\
\hline & V16 & $\begin{array}{l}\text { Familiarizado con lugares } \\
\text { similares }\end{array}$ & \multicolumn{4}{|c|}{ Eliminada } \\
\hline & V17 & Buena reputación & 0.849 & 12.913 & 0.673 & 0.327 \\
\hline \multirow{6}{*}{$\begin{array}{l}\text { Emoción } \\
\text { (Agrado) }\end{array}$} & V18 & Feliz /infeliz & 1.000 & 17.172 & 0.756 & 0.244 \\
\hline & V19 & Contento/Enfadado & 1.658 & 12.650 & 0.329 & 0.671 \\
\hline & V20 & Encantado/Descontento & 1.637 & 12.583 & 0.346 & 0.654 \\
\hline & V21 & Alegre/Triste & 1.799 & 13.054 & 0.210 & 0.790 \\
\hline & V22 & Ilusionado/Desilusionado & 1.769 & 12.976 & 0.236 & 0.764 \\
\hline & V23 & Entretenido/Aburrido & 1.742 & 12.902 & 0.259 & 0.741 \\
\hline \multirow{8}{*}{ confianza } & V24 & $\begin{array}{l}\text { Confianza en la competencia } \\
\text { profesional }\end{array}$ & 1.000 & 16.467 & 0.559 & 0.441 \\
\hline & V25 & $\begin{array}{l}\text { Creencia en excelentes } \\
\text { recursos técnicos }\end{array}$ & 1.130 & 16.612 & 0.437 & 0.563 \\
\hline & V26 & $\begin{array}{l}\text { Experiencia en la } \\
\text { comercialización }\end{array}$ & 1.176 & 17.180 & 0.390 & 0.610 \\
\hline & V27 & $\begin{array}{l}\text { Creencia cumple sus } \\
\text { promesas }\end{array}$ & 0.925 & 13.927 & 0.623 & 0.377 \\
\hline & V28 & $\begin{array}{l}\text { Creencia conoce a sus } \\
\text { clientes }\end{array}$ & 1.112 & 16.373 & 0.456 & 0.544 \\
\hline & V29 & Información detallada & 1.033 & 15.367 & 0.530 & 0.470 \\
\hline & V30 & Satisfacción hacia el cliente & 1.060 & 15.713 & 0.505 & 0.495 \\
\hline & V31 & $\begin{array}{l}\text { Características acordes a mis } \\
\text { gustos y preferencias }\end{array}$ & 1.081 & 15.985 & 0.485 & 0.515 \\
\hline \multirow{7}{*}{ Satisfacción } & V32 & Satisfacción con la estancia & 1.000 & 15.439 & 0.334 & 0.666 \\
\hline & V33 & $\begin{array}{l}\text { Cumplimiento de } \\
\text { expectativas }\end{array}$ & 1.068 & 26.371 & 0.240 & 0.666 \\
\hline & V34 & $\begin{array}{l}\text { Satisfecho con el trato } \\
\text { recibido }\end{array}$ & 0.967 & 22.779 & 0.376 & 0.760 \\
\hline & V35 & Acertada visita al lugar & 1.083 & 26.981 & 0.218 & 0.782 \\
\hline & V36 & $\begin{array}{l}\text { Entre los mejores lugares } \\
\text { visitados }\end{array}$ & 0.931 & 21.583 & 0.423 & 0.577 \\
\hline & V37 & He disfrutado el lugar & 1.012 & 24.306 & 0.318 & 0.682 \\
\hline & V38 & No me arrepiento de la visita & 0.958 & 22.478 & 0.388 & 0.612 \\
\hline
\end{tabular}




\section{Cuadro 5}

Matriz de correlaciones entre las variables latentes

\begin{tabular}{ccccc}
\hline & AGD & CNF & SAT & REPT \\
\hline AGD & 1.000 & & & \\
\hline CNF & 0.502 & 1.000 & & \\
\hline SAT & 0.437 & 0.692 & 1.000 & \\
\hline REPT & 0.360 & 0.660 & 0.460 & 1.000 \\
\hline
\end{tabular}

\section{Gráfica 2}

\section{Resultados de la estimación del modelo final del path análisis realizado}

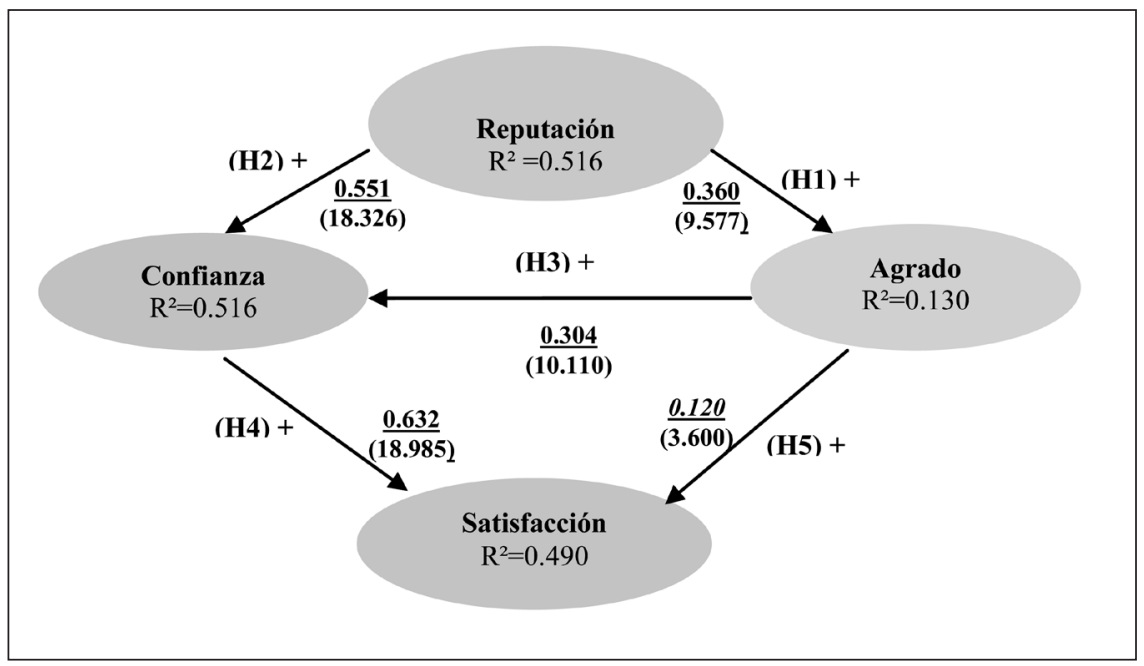

*Nota: la hipótesis H5 es significativa al 90\%.

Se observa en estos resultados que se cumplen todas las hipótesis propuestas a excepción de la H5 que se cumple parcialmente. La H1 se corrobora y resulta ser una hipótesis novedosa porque no hay trabajos que la hubieran tratado anteriormente. Por ello, cuanto mayor sea la reputación que transmite el destino turístico, ésta se observará reflejada en el turista y, en consecuencia, éste sentirá mayor nivel de agrado en sus emociones por ese destino turístico $(\lambda=0.360, \mathrm{p}<0.05)$. Por lo que respecta a la $\mathrm{H} 2$, ésta queda confirmada, lo que nos indica que cuanto mayor sea la reputación de un destino turístico, ésta influirá positivamente en la confianza que siente el turista por ese destino turístico; es decir, a mayor reputación que el destino envíe al mercado, mayor estímulos en la confianza del viajero $(\lambda=0.551, \mathrm{p}<0.05)$. En cuanto 
a la H3, ésta también se confirma, pues a mayor emoción (agrado) que sienta el turista hacia un destino turístico, ésta influirá de manera positiva en la confianza del turista por el destino turístico. Entonces, desde el supuesto de una hipótesis nueva aportamos que las emociones en su dimensión independiente de agrado son formadoras de la confianza en el turista $(\lambda=0.304, \mathrm{p}<0.05)$. La H4 igualmente se verifica y se percibe que la confianza que siente el turista hacia un destino turístico influye positivamente en la satisfacción de éste por el lugar; así, su satisfacción se verá acrecentada en la medida que el turista confié en el destino turístico. Por último, la H5 se confirma parcialmente, ya que es significativa al 90\%, lo que nos indica que si el destino estimula en mayor medida las emociones (agrado), éstas influirán positivamente en la satisfacción del turista por el destino turístico; es decir, a mayor estímulo conseguido de las emociones, mayor satisfacción.

\section{Conclusiones e implicaciones}

En este estudio hemos podido demostrar el poder que tiene la reputación de marca de un destino turístico para incentivar la confianza y las emociones (agrado) positivamente; esta contribución esencial se manifiesta al disminuir el problema de selección adversa en el turista cuando éste no tiene parámetros tangibles de comparación. Al mismo tiempo, la reputación se muestra esencial como señal generadora de confianza (Doney y Cannon, 1997; Bennet y Gabriel, 2001; Bart et al., 2005). Sin duda, se observa que la buena reputación como valor histórico, adicionada e inmersa, se tornará acrecentada en la medida que los gestores de un destino turístico la incrementen con acciones positivas de señalización para el mercado. Así, se corrobora que el consumidor, ante un entorno en el cual prevalezca la incertidumbre, buscará señales como la reputación de un destino turístico en el mercado. Igualmente, se potencializa el uso de la teoría de señales dentro del marketing (Akerlof, 1970; Selnes, 1998; Erdem, 1998; Kirmani y Rao, 2000; San Martín, 2003).

Por otro lado, una nueva implicación que obtenemos de esta investigación es la confirmación de la confianza que el turista deposita en el lugar como fruto de la experiencia vivida a través del contacto con el entorno, lo cual se manifiesta, al mismo tiempo, en la satisfacción total alcanzada por el viajero. Asimismo, es de reconocer el papel de las emociones (agrado) en la confianza; sin embargo, se observa que en la satisfacción, las emociones (agrado) del turista no tiene un efecto mayúsculo; probablemente el efecto sea más valorado en la disconfirmación positiva de sus expectativas más que en la propia satisfacción global del visitante. De 
tal modo, el alto poder explicativo de un modelo que ha considerado los aspectos cognitivos y emocionales de la satisfacción, por el cual el turista evalúa su nivel de satisfacción, ha resultado conveniente por los hallazgos obtenidos. Por su parte, los corolarios provenientes de la confianza confirman de nuevo el impacto que tiene esta variable en el enfoque de marketing relacional en los consumidores (Wetzels et al. 1998; Ganesan, 1994; Morgan y Hunt, 1994; Doney y Cannon, 1997; Bart et al. 2005).

En cuanto a las contribuciones de este trabajo a la parte afectiva del turista, se confirma que las emociones (agrado) ayudan a incentivar la confianza en un destino turístico y en todos los gestores que intervienen en él. Es notable el uso de las emociones (agrado) en marketing para explicar el comportamiento afectivo del consumidor tras su vivencia de ocio y placer (Donovan y Rossiter, 1982; Bigné y Andreu, 2004; Bigné et al., 2005; Yüksel, 2007; De Rojas y Camarero, 2008).

Con esta investigación se profundiza en la comprensión sobre el comportamiento que tiene el turista en un destino turístico ante la asimetría de información que impera en los mercados (teoría de señales), en la parte relacional (procedente del marketing de relaciones) y en la parte afectiva (procedente de la psicología ambiental).

Este estudio tiene varias limitaciones. En primer lugar, los antecedentes culturales de los encuestados (españoles) podrían haber influido en su interpretación de las emociones (agrado), creando así un sesgo potencial en esta medida; sin embargo, los resultados de este estudio sólo se pueden generalizar a destinos similares al estudiado en México con una mezcla de turistas similares. También es conveniente evaluar otro tipo de señales como la calidad, el precio, las garantías o la publicidad del destino turístico. Desde el punto de vista del marketing de relaciones es conveniente evaluar el compromiso temporal y la lealtad que el turista presenta por el lugar; y desde las emociones, otros entornos de ocio y placer.

En suma, como líneas futuras de investigación cabe destacar la necesidad de analizar la repetición de la visita del turista al destino turístico tratado, la creación de lealtad y el compromiso temporal e inclusive el fuerte valor de recomendación por el efecto boca-oído, transferido a los amigos y familiares. En el rubro de la lealtad habría que estudiar la implicación que ésta tiene hacia un destino turístico, considerando su propia naturaleza intangible y habiendo tantas opciones de lugares en el mundo. Resulta un área de estudio adicional para tratar la fuerte, mediana o nula 
implicación por los productos turísticos inmersos en el propio destino turístico. Sobre todo que la lealtad está dada a productos que contienen parámetros de fuerte repetición de compra con altos márgenes de ventas y tras la perspectiva de largo plazo. Teniendo en cuenta esto, los clientes no son absolutamente leales a una marca o a un destino determinado, pues su lealtad aumentará en la medida que se mejore su fidelización a través del marketing de relaciones. Por otro lado, variables como la inseguridad y el narcotráfico que apalean la reputación y la imagen de México resultan pertinentes considerarse en nuevos trabajos. Indudablemente, futuras investigaciones deben indagar si las relaciones de este modelo propuesto subsisten en turistas de otras nacionalidades.

No obstante, dentro de nuestras implicaciones profesionales, anotamos que el cliente fiel será accesible a la adquisición de nuevos productos desarrollados por el destino turístico y dentro del cual puede llevarse a cabo la venta cruzada de otros productos turísticos. A raíz de ello, la innovación de nuevos productos turísticos o mejoras desarrolladas en los servicios de la organización será mejor acogida. Muy a nuestro pesar, actualmente lo que se está viviendo en los micro destinos que componen el destino turístico en su totalidad, como en el caso de Quintana Roo (Cancún, Riviera Maya) y en zonas de los estados de Tabasco y Campeche, es el efecto de un marketing de transacciones, el cual resulta en clientes que tienen un corte horizonte temporal y, en consecuencia, dejan poco margen en la operación de cara al servicio brindado por todos los gestores del destino turístico. El efecto de influenza en suma se visualiza como una baja temporalidad, pero que sin duda ha puesto a prueba la fidelización del target o mercado objetivo.

\section{Referencias}

Aaker, D.A. (1996). Construir marcas poderosas. Barcelona: Ediciones Gestión 2000.

Agarwal, J. y N. K. Malhotra (2005). An integrated model of attitude and affect: theoretical foundation and an empirical investigation. Journal of Business Research 58: 483-493.

Akerlof, G.A. (1970). The market for "Lemons": Qualitative uncertainty and the market mechanism. Quaterly Journal of Economics 86: 488-500. 
(2002). La macroeconomía conductual y la conducta macroeconómica. Revista Asturiana de Economía 25: 7-47.

Bagozzi, R. P., M. Gopinath y P.U. Nyer (1999). The Role of Emotions in Marketing. Journal of the Academy of Marketing Science 27: 184-206.

y Y. YI (1988). On the evaluation of structural equation models. Journal of Marketing Science 6 (1): 74-94.

(1997). Goal-directed behaviours in marketing: the role of emotion, volition, and motivation. Psychology and Marketing 4 (3): 309-313.

Barber, B. (1983). The logic and limits of trust. New Brunswick, NJ: Rutgers University Press.

Bart y Shankar, V., F. Sultan y G.L. Urban (2005). Are the drivers and role of online trust the same for all web sites and consumers? A large-scale exploratory empirical study. Journal of Marketing 69 (4): 133-153.

Bellman, S., G. L. Lohse y E. J. Johnson (1999). Predictors of Online Buying Behavior. Communications of the ACM 4 (12): 32-38.

Bennett, R. y H. Gabriel (2001). Reputation, trust and supplier commitment: the case of shipping company/seaport relations. Journal of business and Industrial Marketing 16 (6): 424-438.

Bergen, M., S. Dutta y O.C. Walker JR. (1992). Agency relationships in marketing: a review of the implications and applications of agency and related theories. Journal of Marketing 56: 1-24.

Berry, L.L. (1983). Relationship marketing. Berry, L.L., G.L. Shostack y G.D. Upah Emergin perspectives on service marketing, en American Marketing Association, Chicago IL: 25-28.

(1995). Relationship Marketing of Services-Growing Interest, emerging Perspectives. Journal of the Academy of Marketing Science 23 (4): 236-245. 
Bigné, J.E. y L. Andreu, L. (2004). Modelo cognitivo-afectivo de la satisfacción en servicios de ocio y turismo. Cuadernos de Economía y Dirección de la Empresa 21: 89-120.

y J. Gnoth (2005). The theme park experience: an analysis of pleasure, arousal and satisfaction. Tourism Management 26 (6): 833-844.

A. S. Mattila y L. Andreu (2008). The impact of experiential consumption cognitions and emotions on behavioral intentions. Journal of Services Marketing 22(4): 303-315.

Buttle, F. (1996). Where do we go now in relationship marketing? Relationship Marketing. Theory and Practice. London: Paul Chapman Publishing: 188-195.

Chu, W. y W. Chu (1994). Signalling quality by selling through a reputable retailer: an example of renting the reputation of another agent. Marketing Science 13 (2): 177-189.

Cohen, J.B. y C. S. Areni (1991). Affect and Consumer Behavior. Handbook of Consumer Behavior, A. Robertson y H. Kassarjian. Englewood Cliffs, NJ: Prentice Hall:183-240.

Cristopher, M., A. Payne y D. Ballantyne (1991). Relationship Marketing. UK: Oxford.

Cronin, J. J., M. K. Brady y G.T.M. Hult (2000). Assessing the effects of quality, value and customer satisfaction on consumer bahavioral intentions in service environments. Journal of Retailing 76 (2): 193-218.

De Rojas, M. y M. C. Camarero (2006). Experience and satisfaction of visitors to museums and cultural exhibitions. International Review on Public and Non Profit Marketing 3 (1): 49-65.

(2008). Visitors` experience, mood and satisfaction in a heritage context: evidence from an interpretation center. Tourism Management 29: 525-537.

Doney, P.M y J.P. Cannon (1997). An Examination of the nature of trust in buyerseller relationships. Journal of Marketing 61 (2): 35. 
Donovan, R.J. y J.R. Rossiter (1982). Store atmosphere: An environmental psychology approach. Journal of Retailing 58: 34-57.

Dwyer, F. R, P. H. Schurr y O.H. Sejo (1987). Developing buyer-seller relationships. Journal of Marketing 51 (2):11-27.

Erdem, T. y J. Swait (1998) Brand equity as a signalling phenomenon. Journal of Consumer Psychology 7 (2): 131-158.

y J. Louviere (2002). The Impact of brand credibility on consumer price sensitivity. Journal of Research in Marketing 19 (1): 1-19.

Evans, J. y L. Laskin (1994). The relationship marketing process: A conceptualisation and application. Industrial Marketing Management 23: 439-52.

Fernández, M. y J. D. Martín (2006). La confianza y el compromiso como factores clave del éxito de las relaciones comerciales: una aplicación empírica en el sistema de franquicia. Revista Europea de Dirección y Economía de la Empresa 15 (1): 77-100.

Fombrun, C, N. Gardberg y J. Sever (2000). The Reputation Quotient: a multistakeholder measure of corporate reputation. Journal of Brand Management 7 (4): 241-255.

Frijda, N. H. (1986). The emotions. Reino Unido: Cambridge University Press.

Ganesan, S. (1994). Determinants of long-term orientation in buyer-seller relationships. Journal of Marketing 58 (2): 1.

Garbarino, E. y M.S. Johnson (1999). The different roles of satisfaction, trust, and commitment in customer relationship. Journal of Marketing 63: 70-87.

Gilpin, S. C. (1996). Relationship Marketing. Theory and Practice. Paul Chapman Publishing: 145-158.

Goossens, C. (2000). Tourism information and pleasure motivation. Annals of Tourism Research 27: 301-321. 
Gummesson, E. (1996): Relationship marketing and imaginary organizations: a synthesis. European Journal of Marketing 30 (2): 31-44.

Hall R. (1993). A framework linking intangible resources and capabiliites to sustainable competitive advantage. Strategic Management Journal 14 (8): 607-618.

Havlena, W.J. y M.B. Holbrook (1986). The varieties of consumption experience: comparing two typologies of emotion in consumer behavior. Journal of Consumer Research 13 (3): 394-404.

Hawes, J. M., K. E. Mats y J. E. Swan (1989). Trust earning perceptions of sellers and buyers. Journal of Personal Selling and Sales Management 9: 1-8.

Herbig, P. y J. Milewicz (1993). The relationship of reputation and credibility to brand success. Journal of Consumer Marketing 10 (3): 18-24. $35-45$.

Hess, J. y J. Story (2005). Trust-based commitment: multidimensional consumerbrand relationships. Journal of Consumer Marketing 22 (6): 313-322.

Ibrahim, E. y J. Gill (2005). A positioning strategy for a tourist destination, based on analysis of customers` perceptions and satisfactions. Marketing Intelligence and Planning 23 (2/3): 172-188.

Jackson, B. B. (1985). Build customer relationships that last. Harvard Business Review. Noviembre-diciembre: 120-128.

Kirmani, A. y P. Wright (1989). Money talks: perceived advertising expense and expected product quality. Journal of Consumer Research 16: 344-353.

Kozak, M. (2001). Repeaters` behaviour at two distinct destinations. Annals of Tourism Research 28 (3): 784-807.

Kreps, D.V. y R. Wilson (1982). Reputation and imperfect information. Journal of Economic Theory 27: 253-279. 
Lacey, R. (2007) Relationship drivers of customer commitment. Journal of Marketing Theory and Practice 15 (4): 315-333.

Lara G. (2006). La investigación arqueológica en Honduras: lecciones aprendidas para una futura proyección. Revista Pueblos y Fronteras Digital 2: 1870-4115.

Lassala, C., C. Ruiz y S. Sanz (2010). Implicaciones de la satisfacción, confianza y lealtad en el uso de los servicios bancarios online. un análisis aplicado al mercado español. Revista Europea de Dirección y Economía de la Empresa 19 (1): 27-46.

Lemon, K. N., T. B. White y R. S. Winer (2002). Dynamic customer relationship management: incorporating future considerations into the service retention decision. Journal of Marketing 66: 1-14.

Macintosh, G. y L. S. Lockshin (1997). Retail relationship and store loyalty: a multi-level perspective. International Journal of Research in Marketing 1 (14): 487-497.

Mano, H. y R. L. Oliver (1993). Assessing the dimensionality and structure of the consumption experience: evaluation, feeling, and satisfaction. Journal of Consumer Research 20 (20): 451-466.

Mayer, R. C., J. H. Davis y F. D. Shoorman (1995). An integrative model of organizational trust. Academy of Management Review 20 (3): 709-734.

Mehrabian, A. y J. A. Russell (1974). An approach to environmental psychology. Cambridge, Mass: MIT Press.

Mitchell y Vincent-Wayne (1999). Consumer perceived risk: conceptualisations and models. European Journal of Marketing 33 (1): 163-195.

Moorman, C., R. Deshpandé y G. Zaltman (1993). Factors affecting trust in market research relationships. Journal of Marketing 57: 81-101.

Morgan, R.M. y S. D. Hunt (1994). The commitment-trust theory of relationship marketing. Journal of Marketing 58 (3): 20-38. 
Nurosis, M. J. (1993). SPSS. Statistical data analysis. SPSS Inc.

Obiol E. M. (2002). Marcas turísticas y territorio: un análisis geográfico del turismo valenciano. Cuadernos de Turismo 9: 85-101.

Oliver, R.L. (1980). A cognitive model of the antecedents and consequences of satisfaction decisions. Journal of Marketing Research 17: 460-469.

(1993). Cognitive, affective, and attribute bases of the satisfaction response. Journal of Consumer Research 20: 418-430.

(1997). Satisfaction: A Behavioural Perspective on the Customer. New York: Mc-Graw Hill.

Peter, J. P. y J.C. Olson. (1999). Consumer Behavior and Marketing Strategy. 5a ed., New York: McGraw-Hill.

Ramírez, C. (2006). Marketing turístico. México: Trillas.

Real, J. E., R. García, M. S. Rodríguez y C. Arce (1996). Datos del estímulo único versus datos de elección preferencial en estudios sobre calidad ambiental. Psicothema 8 (3): 533-541.

Russell, J. A. (1980). A circumplex model of affect. Journal of personality and Social Psychology 39: 1161-1178.

y G.A. Pratt (1980). A description of the affective quality attributed to environments. Journal of Personality and Social Psychology 38: 311-322.

Ruyter, K. y M. Wetzels (1999). Commitment in auditor-client relationships: antecedents and consequences. Accounting Organizations and Society 24: 57-75.

San Martín, H. (2005. Estudio de la imagen de destino turístico y el proceso global de satisfacción: adopción de un enfoque integrador. Tesis doctoral. Universidad de Cantabria.

(2003). La relación del consumidor con las agencias de viajes. España: Universidad de Burgos. 
Sanzo, M., M. Santos, R. Vázquez y L. Álvarez (2003). The effect of market orientation on buyer-seller relationship satisfaction. Industrial Marketing Management 32(4): 327-345.

Selnes, F. (1998). Antecedents and consequences of trust and satisfaction in buyerseller relationships. European Journal of Marketing 32(3/4): 305-322.

Steenkamp, J. B. y H. Trip. (1991). The use of LISREL in validating marketing constructs. International Journal of Research in Marketing 8: 283-299.

Stone, R. N. y J. B. Manson (1997). Relationship management: strategic marketing's next source of competitive advantage. Journal of Marketing Theory and Practice: 8-19.

Ward, L. M. y J. A. Russell (1981). The psychological representation of molar physical environments. Journal of Environmental Psychology 110:121-156.

Wetzels, M., K. Ruyter y M. V. Birgelen (1998). Marketing service relationships: the role of commitment. Journal of Business and Industrial Marketing 13 (4/5): 406-423.

Wirtz, J. y J. E. G. Bateson (1999). Consumer satisfaction with services: integrating the environment perspective in services marketing into the traditional disconfirmation paradigm. Journal of Business Research 44: 55-66.

Yüksel, A. y F. Yüksel (2007). Shopping risk perceptions: effects on tourists emotions, satisfaction and expressed loyalty intentions. Tourism management 28: 703-713.

(2007). Tourist shopping habitat: effects on emotions, shopping value and behaviours. Tourism management 28: 58-69.

Zaichkowsky, J. L. (1985). Measuring the involvement construct. Journal of Consumer Research 12 (4): 341-352.

Zeithalml, V. A., L. Leonard, Berry y Parasuraman (1996). The behavioural consequences of service quality. Journal of Marketing 60: 31-46. 
Zins, A. H. (2001). Relative attitudes and commitment in customer loyalty models. Some experiences in the commercial airline industry. International Journal of Service Industry Management 12 (3): 269-294. 